\title{
Pós-Editorial
}

\section{Covid-19 e religião: sindemia, sindemônio e o desafio de compreender o religioso}

Covid-19 and religion: syndemic, syndemoniumandthe challenge of understanding the religious

Emerson José Sena da Silveira* Waldney de Souza Rodrigues Costa**

d.

https://doi.org/10.29327/256659.12.1-14

Deus disse ainda:

'Chore, povo de Jerusalém. Corte os seus cabelos e jogue fora. Cante música triste no alto dos montes, pois eu, o Senhor, estou irado e abandonei o meu povo.' [...] A terra ficará deserta. E eu acabarei com os gritos de alegria e de felicidade e com o barulho alegre das festas de casamento, tanto nas cidades de Judá como nas ruas de Jerusalém.

Jeremias 7, 29-30, 34

A cada vez que trabalhamos nesse ensaio reiniciamos a contagem. Na última passávamos de 420 mil mortos e 15 milhões de casos. Na data da publicação provavelmente será muito mais. Meio milhão é logo ali. Um loop interminável nos coloca, provisoriamente, num platô altíssimo.Os dados são assustadores, mais ainda queos descritos no próximo parágrafo. Era impossivel preparar um comentário ao dossiê que a Plura entrega nesse novo número, sem uma atualização mínima de como segue a nossa situação. Uma passagem de olhos pelos portais dos grandes veículos de comunicação e lê-se: TCU acusa governo de 'abuso de poder' e omissão com kit intubação... ${ }^{1}$. Parece um pesadelo surreal e sem fim o que vivemos em nossa terra natal. A tarde dominical está morna, nublada e da janela se contempla alguns pássaros que cantam.Diante da hecatombe intencio-

"Doutor em Ciência da Religião, antropólogo, professor associado do Departamento de Ciência da Religião da Universidade Federal de Juiz de Fora (UFJF). E-mail: emerson.pesquisa@gmail.com.

${ }^{*}$ Doutor em Ciência da Religião pela Universidade Federal de Juiz de Fora (UFJF). Professor e chefe do Departamento de Ciências da Religião da Universidade do Estado do Rio Grande do Norte (UERN). E-mail: professordney@gmail.com. 
nalmente provocada desde as altas esferas federais (leia-se presidência da República e sua família), as religiõesestãoafetadas grandemente, em efervescência,atravessadas por pressões pela abertura de templos, conflitos internos entre lideranças e liderados, negaçõesmassivas da ciência, recomendações sanitárias e médicas, adaptações online e embrionários movimentos de crítica política entre evangélicos, espíritas e católicos, estendendo-se pelo campo religioso brasileiro.

Desse começo, voltamos ao primeiro concebido numa noite de 25 de março. Perdoe-nos se a leiturase alongar e destoar do quefoi comentado acima, mas estamos em condições históricas singulares.Sob o sol de outono no hemisfério sul, no Ano Segundo da Desolação, terceiro mês, vigésimo quinto dia: 303,7 mil mortos olham espantados e incrédulospara aqueles que ainda estão vivos e para aqueles que governam, assentados em suas cadeiras de marfim e mogno. Mais 97.586 mil contaminados ${ }^{2}$ são engolfados num tsunami que, em 24 horas, trouxe em suas asas biopolíticas a morte para 2.639 brasileiros: danos aos pulmões, incapacidade de respirar, implosão ensanguentada do sistema respiratório e, daí, as reações em cadeia devoraram os $\operatorname{corpos}^{3}$. 6.370 brasileiros jazem em leitos, quase jazigos provisórios, ansiosos por alguma sobrevida viabilizada pelo anjo da morte presidencial, segundo o Conselho de Secretários de Saúde dos Estados. ${ }^{4}$ Morreram no chão de Unidades de Saúde uns tantos; morreram em casa, outros, ainda sem contagem exata. Os cemitérios realizaram enterros noturnos, a evocar recordações imagéticas de pestes que atravessaram séculos e, como ondas, rebateram sobre as aldeias e cidades europeias; ou doenças contagiosas em outros países, culturas e civilizações ao longo de suas próprias temporalidades. E, nesses casos, com grande participação dos sistemas religioso-míticos. É imensa, ainda por se contar e compreender, a legião humana com graves danos neurológicos, nefrológicos, hepáticos, circulatórios, psicológicos e psiquiátricos que arrastarão suas cicatrizes por uma vida inteira.

São os dados oficiais. Não se contam as suspeitas de Covid-19, e as mortes e contaminações decorrentes. Uma doença política em essência. Ou uma expressão do biopoder, para lembrar um importante conceito de Michel Foucault (1999; 2010) que às Ciências da Religião e às Ciências Sociais compete urgência para levá-lo ao primeiro plano de discussão acadêmica e de interlocução com a sociedade brasileira. A falsa dicotomia entre natureza/cultura, ou biologia/sociedade, dentre muitas outras, não permitem uma compreensão adequada dos dilemas de nossa época. Porém, à luz de autores como Roberto Esposito 
(2010), Tony Negri e Michael Hardt (2018), dentre outros, talvez possamos melhor deslindar as tramas tecidas entre religião, poder e vírus.

Com essas chaves de leitura percebemos que, na Modernidade,o poder político-econômico é exercido como feixe de relações sobre a vida nua, como corpo coletivo (biopoder) e como corpo individual (anátomo-política), regulando-a, subordinando-a, gerindo-a, de formas menos eugenistas, socialdemocratas, ou mais fascistas: a celebração da vida dos "fortes", da "nação", a "imunidade de rebanho" ou natural. Sob dois pontos de vista essa ideia é um grande equívoco e um horror. Do ponto de vista moral-ético, expor propositadamente uma população inteira ao vírus, para que essa adquira como um todo e "naturalmente" a imunidade (desenvolvimento de anticorpos contra o coronavirus), é levar milhares de vidas à morte por sufocamento e milhares de outras a duradouras e sérias sequelas incapacitantes. E do ponto de vista técnico-científico, a ideia de "imunidade de rebanho" se mostra inviável para doenças em geral, especialmente em relação às causadas por vírus,porque, submetidas a grande circulação, sem controle, produzem novas cepas e variantes. Acredita-se que são dezenas em circulação agora, sendo três delas violentas e mais contagiosas que a versão inicial: a brasileira (de Manaus), a inglesa e a hindu. Em janeiro, o colapso da capital amazonense, após líderes religiosos, empresários e comerciantes resistirem e protestarem contra decretos estaduais e municipais que anunciavam fechamento em dezembro de 2020, foi agônico e trágico. De lá para cá, foi abalada a ideia de grupo de risco: idosos e pessoas com as ditas "comorbidades" (diabetes, cardiopatias, pneumopatias, etc.). Jovens e pessoas sem comorbidades se tornaram maioria nas UTIs e entre os que morrem. Dentro desse grupo, aumentou o número de mulheres gestantes mortas a ponto de o Ministério da Saúde recomendar que se evite a gravidez enquanto durar o enfrentamento da Covid-19. Regiões e cidades inteiras registraram decréscimo populacional: mais mortes do que nascimento.

Mas sabemos que, enquanto durar o atual governo, essa situação não tem data para terminar e quanto mais ele permanece, mais a ideia de imunidade de rebanho se aprofunda com todas as suas consequências nefastas. Essa ideia é o pilar no qual Bolsonaro e seu séquito de apoiadores radicais assentam a biopolítica da devastação. Incluem-se aqui, os cristãos reacionários (evangélicos e católicos), pois aqui intervém ideia de "vontade de Deus, Ele tira, Ele põe, Ele deixa perecer". Daí não deve haver fechamento ou lockdown, todos devem trabalhar e devem ser livres para usar máscaras ou não, vacinar-se ou não. As expressões 
presidenciais: "gripezinha", "não ser maricas" e "enfrentar de frente", "vamos todos morrer mesmo", dentre muitas outras, evidenciam o arraigamento dessa noção. Bolsonaro se associou a um filamento de RNA através do qual escoa a biopolítica desejada por uma parte da sociedade.

Muitas igrejas evangélicas pentecostais/neopentecostais e seus líderes, grupos espíritas kardecistas e católicos reacionários, são ardorosos defensores dessa política e a base ideológica é a da liberdade individual acima de tudo e todos, contra o Estado e contra as leis e regras por ele impostas para controlar o contágio ou tentar alguma redistribuição de riqueza.Vimos algo disso nos artigos desse número, mas há muito mais o que registrar. Essas ideias podem ser encontradas em poderosos políticos, como Margaret Thatcher que, repetindo uma certa história enviesada, nominalista, uma meia-verdade com muito de ideologia, afirmou que a sociedade não existia, apenas o indivíduo, interpretando o economista Friedrich Hayek. Entre os católicos brasileiros esse apoio parece ser bem menor devido a uma conjugação de elementos, do Papa Francisco às dinâmicas históricas e estruturais do catolicismo. Em 27 de março, diante de uma praça de São Pedro, vaticano, sede do papado, vazia, em fim de tardem e um começo de noite chuvoso, nublado, o Papa Francisco celebrou sozinho um ato litúrgico dos mais impressionantes, que correu mundo, por sua força moral, estética, afirma, a benção Urbi et Orbi. 5

Cabe destacar que o costume de ver as doenças como algo da natureza, o desabar de um golpe, o proferir de um oráculo certeiro do destino, o amargor entravado de uma leitura religiosa fatalista, a marcha de castigo divino na mão canhota da divindade, é o que precisa ser suspenso, retraído, passado ao fogo do crivo de uma reflexão fina e crítica. Alia-se a ele um certo senso-comum, advindo do cientificismo, que separa em gavetas a doença, a natureza e a sociedade.

Diante isso, sem prejuízo do largo uso do termo pandemia, consagrado pela imprensa e pela sociedade em geral, após a observação de tudo o que foi apresentado nesse número da Plura, pensamos que o conceito de sindemia criado por Merril Singer (2009) e ventilado em periódicos da área da saúde na segunda metade de 2020 para se referir à situação com a Covid-19, descreve de maneira mais precisa aquilo que vivemos. E, assim, propomos outro termo, sindemônio, um neologismopara caracterizar o agravamento vivido no Brasil, cuja descrição de sua face religiosa pode ser encontrada nessedossiê. 
O conceito de sindemia, vindo da antropologia médica e suas investigações no campo da antropologia da doença e da saúde (em especial AIDS, Ebola, Influenza e doenças viróticas ou infeciosas de longa permanência), foi re-proposto pela prestigiosa revista cientifica The Lancet. Em seus editoriais, foi uma das primeiras revistas consagradas a criticar Trump e Bolsonaro pela condução do poder estatal na gestão da Covid-19. Algo pouco visto no contexto da grande área das Hard Sciences, que geralmente se movem na esteira da velha dicotomia natureza/cultura, incapaz de iluminar as dinâmicas que geram uma doença, fazendo interagir, de maneira simultânea e inseparável, um sem-número de elementos: urbanos, econômicos, sociais, políticos, sanitários, epidemiológicos, biológicos, arquiteturais, religiosos, numa sinergia que potencializa seus danos e impactos, encavalando-se com outras doenças e problemas sociais. Daí, syn/sin, do grego, tudo junto, produzindo a enfermidade, na tentativa de melhor caracterizar processos cuja situação tem sidodescrita, ora como epidemia, uma doença, em geral infecciosa e transitória, que ataca ligeiro, ao mesmo tempo e lugar, grande número de indivíduos; ora como pandemia, que se refere a uma epidemia que atinge um vasto território.

Sindemônio, por sua vez, é um neologismo proposto nesse comentário final ao dossiê para caracterizar a concorrência, a interação, o entrelaçamento e a retroalimentação entre problemas estruturais ou conjunturais, anteriores ou posteriores, à sindemia de Covid-19: depauperação profunda da sociedade, racismo, falhas da democracia representativa, inação política das oposições institucionais, fome, desmatamento, polimilícia (fusão entre milícias e polícias, aquelas compostas por ex-policiais ou policiais, e estas em relação sinérgica com a criminalidade), narco-milico-evangelismo (mistura do tráfico com igrejas evangélicas e milícias ou grupos de extermínio e exploração), enfraquecimento dos canais clássicos de participação política, atomização social, educação com falhas estruturais, exaustão do sistema público de saúde, sobrecarga e desestruturação em cadeia das ações de saúde e políticas públicas, desindustrialização, inflação e estagnação, perda de riqueza e renda por parte das classes populares e média. Ou seja, trata-se de efeitos sindêmicos encavalados numa proporção devastadora. Não se ignora, decerto, as tantas histórias de superação da Covid-19, de solidariedade nesse momento dificil, dos tantos movimentos de luta social, de combate à fome e ao racismo, inclusive com forte participação religiosa, dentre outros aspectos, que também constam nesse dossiê. Mas queremos destacar as dimensões da gravidade da conjuntura em que estamos. 
Quandoos dois conceitos, sindemia e sindemônio, são associados à ideia de biopolítica e biopoder, a compreensão de nossa situação aumenta e se percebe como o virus funde-se a contextos globo-locais, governos, pessoas, potencializando os poderes de destruição das entidades fundidas, pois, por elas, a doença respiratória-infecciosa vive - contaminando os organismos humanos, entrando em mutação. O mero vírus da gripe comum, de alta propagação e, felizmente, baixa letalidade, se comparado, a outros, mostra que se, um estado de mutação for atingido, a possibilidade de erradicação é fraca. Basta pensar que as vacinas comtra a gripe comum saíram dos laboratórios, mas são válidas apenas para aquele ano no qual a variante impera, pois logo depois surgem variações devido à circulação de pessoas em contato intenso.Algo parecido pode ocorrer com a Covid-19 e teremos não apenas dois anos de desolação, mas vários, caso a vacinação em massa (entre dois e três milhões por dia), fechamentos mais severos e apoio social e financeiro (aos que não tem renda ou que ficarão prejudicados fortemente, pessoas ou empresas) e protocolos sanitários rígidos (máscaras e distanciamento social) não forem adotados com um plano de gestão multissistêmico da crise. Mas isso significaria tirar o bolsovirusdo poder...

Mas, o que é Bolsovirus?O primeiro autor que se tem notícia a usar a ideia de fusão entre vírus e presidente, e teorizar a respeito, inspirado nas ficções de Stan Lee (Marvel), é o filósofo Paulo Ghiraldelli (CABELO; GHIRALDELLI, 2020). Um uso que aponta para o potencial de compreensão que as modernas ficções de quadrinhos guardam para situações inquietantes e terrificas.Todavia, tirar o bolsovirusnão é algo que se possa deixar para as eleições de 2022, precocemente discutidas pelos partidos de centro, direita e esquerda. O mecanismo de impeachment, usado duas vezes, derrubou dois presidentes, Collor e Dilma, por evidências pequenas se as comparamos com as evidências de crime cometidas dia sim e dia também, por Bolsonaro. A ideia de impeachment sofre um claro bloqueio na imprensa e na ação prática dos partidos de centro e de esquerda. São mais de uma centena de processos de impeachment que estão na fila, represados pelo presidente da câmara que se omite, o anterior e o atual. Parece haver um pacto tácito para obstaculizar ao máximo o impeachment: o centrão que tenta extrair o máximo de cargos e dinheiro; parte do empresariado (ruralistas, mineradores selvagens etc.) e líderes e partidos de oposição. Grandes líderes de esquerda disseram que não há tempo, o que não é verdade, pois durante a sindemia tivemos o impeachment de um governador, o do Rio de Janeiro, e dois pro- 
cessos contra o governador de Santa Catarina. Não se mobiliza uma grande frente, não se criam formas de luta, já que as ruas não podem ser ocupadas fisicamente por aglomerações. Há iniciativas isoladas que tentam vencer esse bloqueio, mas rebatem numa parede. Os órgãos de imprensa criticam acerbamente o governo, mas poucos pedem e insistem no mecanismo politico-jurídico que usamos em um curto período (em 1992 e em 2016). Fica uma pergunta, crucial e grave: por que tantos crimes cometidos por um presidente não estão dando, por enquanto, origem a um processo como o que já ocorreu em nossa história duas vezes, com participação, a favor e contra, das religiões e igrejas? A situação poderá mudar e termos uma solução mais rápida do que uma lenta agonia, ou seja, a aposta nas eleições de 2022, apesar das milhares de mortes que ocorrerão? Só o processo histórico vivo vai mostrar...

A permanência do quadro sindemônico sem uma intervenção e reorganização mais rápida, ainda este ano, significa o prolongamento da doença e consequências imprevisiveis para 2023, quando assumiria um novo governo. Se hoje estamos com mais de 400 mil mortos e um rastro de destruição, imagine até chegar janeiro de 2023, num governo hipoteticamente diferente do atual...Há um quadro dantesco, mas, paradoxalmente, os analistas insistem em categorias de entendimento claramente deficitárias e incapazes de dar conta de fenômenos agigantados sob os nossos olhos e guiam-se os militantes politicos por palavras de ordem defasadas, encarquilhadas, de outras épocas. Aumenta-se a confusão, a desorientação e a inércia. Não sabem o mundo em que estamos vivendo, de fato. Aumenta-se com isso, a esperança messiânica na democracia representativa liberal que, justono Brasil, está em crise, encalacrada num sem-número de problemas que vão da inconsistente democracia partidária interna à incapacidade dos partidos de dialogarem com a sociedade e suas transformações, dos vícios estruturais do presidencialismo de coalização às barreiras ao aumento da democracia participativa.

Tome-se em termos de estopim, elemento que, atiçado sobre uma massa de cadeias causais, uma rede de forças sociais e politicas em movimento, acende um pavio que só acaba com a destituição, por vias legais, do mandatário máximo. Um Fiat Elba foi capaz de fazer nascer um movimento de indignação popular - os cara-pintadas, jovens em sua maioria - eretirar uma rede de criminosos que ameaçava tomar conta do governo federal e aprofundar o assalto neoliberal às conquistas socioeconômicas da Constituição de 1988. Uma pedalada fiscal polê- 
mica foi motivo para afastar uma presidenta num tumultuado contexto de ruptura de um pacto de classes e seus agentes (esquerda e elites agrárias, financeiras, burguesas, religiosas) no processo de globalização financeira e neoliberalismo em crise.

Um modo de produzir a vida, e influenciá-la em suas mais diversas áreas, política cultural, subjetiva, religiosa, em curva crescente no mundo desde o ano 1970 e no Brasil desde os anos 1990, não à toa, convergentes com o mássico crescimento de correntes cristãs pentecostais e carismáticas, aclimatadas ao mundo moderno urbano-capitalista, como uma Hidra de Lerna, monstro mitológico.

2020 e 2021 tem sido anos de completa desolação. O bolsonarismo, essa espécie de religião política tingida de populismo de extrema-direita a serviço do avanço do capital, no sentido marxiano-contemporâneo, saiu do controle dos líderes e partidos da situação.Pulularam negacionismo rampante, celebração de remédios prejudiciais (cloroquina, ivermectina, hidroxicloroquina), embates religiosos contra as medidas sanitárias (lockdown, máscaras, vacinas). E os milhares de lutos familiares incrustados na temporalidade interminável ainda não foram capazes de mover os maiores líderes da oposição e seus partidos. Possuem experiência contra e a favor da remoção legal de presidentes, dinheiro (verbas parlamentares e verbas de gabinete), militância engajada e bancada (o segundo partido da Câmara, com 55, é do Partido dos Trabalhadores). No momento que escrevemos, até falam do afastamento do presidente, mas sem entusiasmo. A própria Comissão Parlamentar de Inquérito (CPI) dedicada à apuração da gestão da crise ocasionalmente é desacreditada por comentários ventilados na imprensa. Há parlamentares de direita interessados no impedimento que relatam dificuldades com o envolvimento de representantes da esquerda institucional. Estes últimos encontram-se travados por não-sei-o-quê de pruridos e agora-nãos, alguns claramente eleitorais, mais exatamente eleitoreiros...

Em meio à tempestade negra que dura mais de ano, ouve-se aqui, ali e acolá, algumas vozes fortes, roucas de gritar, mas firmes, vindas de grupos de esquerda não partidários, comunidades e coletivos diversos (indígenas, negras, sindicatos), alguns politicos esparsos. Vozes que pedem desesperadas o remédio legal para casos extremos, como o que vivemos, o impeachment, como forma de impor um freio e uma rearrumação ao cenário desolador. 
O modo neoliberal em ascensão globo-local, se espraiando pela cultura e a sociedade, decorrendo daí, um pouco de caldo narcisista e liberticida (ilusão da liberdade absoluta, acima de tudo e todos), combinado ao caldo religioso reacionário-conservador, uma reação amargurada e agressiva às perdas materiais e simbólicas vividas aos longo dos tempos, a ocupação progressiva da esfera pública e do Estado por essas hostes religioso-reacionárias, a fragilidade da democracia-liberal representativa e a constante emersão da democracia participativopopular, expressa em rebeliões, revoltas e movimentos de massa de cunho igualitarista em nossa centenária história, sendo junho de 2013, um acontecimento plural e singular nesse aspecto.

Desde o Ano I do sindemônio daCovid, contabilizou-se três senadores mortos, um deles importante liderança evangélica conservadora; um cantor-vereador negro, baiano, com grande fama no mundo gospel; padres, bispos, pastores, médicos, prefeitos, vereadores, lideranças religiosas, professores e enfermeiras ceifadas. Uma maioria de corpos idosos pobres, negros, moradores de periferias, desempregados, indígenas, quilombolas. Na boca do bolsovírus, crianças, jovens e adultos sem comorbidades começam a ser mastigados em número crescente, 20, 30 a 40\% do total registrado, e cuspidos em covas, os cemitérios não param sua expansão.

As cepas, as variações e as mutações, tornam mais perigosa a sindemia de Covid-19 aqui, somos um risco global. Quanto mais a doença biopolítica circula, mais entra em mutação e mais desorganiza o ordenamento social, sanitário e econômico. O capital - hoje transnacional e global, muito além do Estado-Nação - falou algumas notas pela boca de economistas, poderosos banqueiros e empresários. Dia 22 de março de 2021, a carta-manifesto evidenciou o descolamento da junção provisória e instável, formada em 2018, entre populismo de extremadireita, religião bolsonarista e o ordenamento neoliberal a serviço do capital transnacional. ${ }^{6} \mathrm{E}$ verdade que tal manifesto contém ideias refutadas na prática por conta de efeitos negativos severos em países europeus, como a de que as escolas devem ser as últimas a fechar e as primeiras a abrir em casos de isolamento social. Porém, em linhas gerais, o texto se coaduna com alguns dos diagnósticos elaborados por filósofos, economistas, sociólogos, médicos sanitaristas, pensadores e pesquisadores, do centro e à esquerda, institucional e não institucional. O que se pode fazer para cortar a cabeça exata da Hidra de Lerna da Covid19, de onde brotam mil outras, cheias de dentes longos e afiados: lockdown seve- 
ro, quiçá nacional, por um período curto, mas suficiente para desarmar as engrenagens biológicas de transmissão, porém, com auxílio financeiro amplo, digno e suficienteàs rendas dilapidadas de grupos socialmente mais vulneráveis e setores econômicos mais afetados.Soma-se a isso uma coordenação nacional para vacinação massiva e acelerada, urbanização, saneamento e arejamento de áreas insalubremente amontoadas, e intensificação do uso de máscaras adequadas.

Em outras palavras, o capital transnacional percebeu que a crise da Covid-19 só pode ter fim se tiver fim em todos os lugares. Quem escreve isso é um economista liberal, Celso Ming (2021), um dos porta-vozes orgânicos das elites burguesas brasileiras, com essas exatas palavras. O que se tentou aqui, em termos políticos, foi um arranjo interventivo, uma intervenção branca no governo do bolsovirus: após uma série de aproximações, iniciadas em maio/junho de 2019 , coroado com um pacto de governabilidade em janeiro/fevereiro de 2021, o centrão e os presidentes do Senado e da Câmara impuseram um comitê de gestão e pressionaram os setores bolsonaristas radicais a serem despedidos do governo, o chanceler Ernesto Araújo e o assessor internacional da presidência, Felipe Martins.

Entre maio-julho de 2020, se lembramos bem, tomou corpo uma revolta popular, após a ressaca das ruas ocupadas pela extrema-direita e direta entre 2015 e 2018. Essa revolta foi inflamada por três estopins: a morte de George Floyd, um afro-americano que, sob o joelho de um policial branco, gritou, "não consigo respirar", mote apropriado pelos movimentos negros; o protesto das torcidas organizadas de futebol, e a greve dos entregadores de comida. Pediam impeachment. A reação dos ideólogos da direita foi criticar e distorcer o sentido correto de terminologias. O pastor Marcos Feliciano criticou-os. Gabriela Prioli, exjornalista da CNN-Brasil, emissora com as digitais da Igreja Universal do Reino de Deus em seu projeto de poder, chamou os manifestantes negros de "genocidas", uma completa perversão do conceito que, hoje, pegou no presidente Jair Bolsonaro ao ponto de sua mais fiel escudeira, deputada Bia Kicis, guindada pelo acordo Centrão-Bolsonaro à presidência da importante Comissão de Constituição e Justiça, tentar proibirseu uso por deputados nas sessões parlamentares. Nenhum partido político ou sindicato envolvido, apenas alguns deputados de esquerda. Ao contrário, a maioria dos líderes e partidos de oposição censurou e largou mão, assim como se desengajaram do movimento de impeachment que esboçou algo em janeiro de 2021. 
As religiões diante da sindemia e do sindemônio agiram de modo diverso. Alguns agentes foram de encontro às ideias da extrema-direita populista, outros vieram ao encontro. A favor da abertura da economia, contra o fechamento de templos, tem-se líderes como Silas Malafaia, líder de parte das Assembleias de Deus (maior grupamento pentecostal brasileiro). O pastor Valdomiro Santiago passou a vender feijões mágicos como forma de combater a Covid-19. Espíritas e católicos bolsonaristas acompanharam esse movimento geral. Mashá muitos grupos religiosos que procuram adaptar-se aos protocolos sanitários e às medidas de fechamento. Pipocaram os cultos online, missas, orações e reuniões adaptadas e reinventadas. Muito disso foi relatado nesse dossiê.

Urge resgatar o núcleo das ideias de Peter Berger (1989), importante sociólogo da religião; o círculo dialético projeção-exteriorização-interiorização, ou seja, os produtos humanos - economia e religião - brotam coletivamente de nossas mãos, sendo exteriorizados em instituições e realidades que são por nós interiorizados e, exatamente por isso, nos aparecem como naturais e dados desde sempre. A religião, nessa perspectiva bergeriana, entra como selamento da plausibilidade, pois firma o arbitrário, o histórico e o temporal, no plano cosmológico e mítico, além deste mundo, como vontade sagrada, imutável e contrária às mudanças. Esse mundo da sindemia e do sindemônio pode parecer natural, mas foi criadopor nós, em sociedade, e por nós pode ser mudado.

Na secularização, em que pese a própria revisão bergeriana, o mundo religioso e o mundo não-religioso não se isolam um do outro, mas se misturam de modo específico, se entrechocam, mutuamente se influenciam: este empresta àqueletécnicas, estratégias e discursos (marketing digital, individualismo narcisista, capitalismo financeiro, consumo gospel); e aquele empresta a este ideias e metáforas religiosas legitimadoras de campanhas culturais e politicas (BERGER, 2017). Como exemplo podemos citar a guerra cultural da "ideologia de gênero" ou o mote da campanha presencial, "E conhecereis a verdade, e a verdade vos libertará", tirado daprofecia bíblica, no Evangelho de João. Quanto a isso, o pior é que na medida em que o bolsovirus foi colocado em marcha,a verdade realmente foi aparecendo. Em um ano, o presidente promoveu 40 aglomerações, minimizou e desprezou o novo coronavírus inúmeras vezes, debochou dos mortos, tentou impor sua ideia de "imunidade de rebanho", disse que não se vacinaria. Papagaiou a liberdade absoluta de todos: a de médicos de receitarem remédios comprovadamente prejudiciais, a de comerciantes e empresários abrirem suas lojas e 
estabelecimentos, a de líderes religiosos considerarem templos serviços essenciais, ainda que, com isso, os contágios aumentem, a doença se agrave e milhares morram. Houve até confusão que o presidente fez questão de fazer entre o lockdown e o estado de sítio. O cume da montanha trevosa se vislumbrou. Em transmissão online dia 25 de março, um ato falho deixou evidente o quanto a figura de Bolsonaro e seu Governo transpiram a fusão com o vírus causador da Covid-19, quando suas palavras foram: "as medidas tomadas contra a vacina tomadas lá atrás" (BOLSONARO, 2021, 1:13). Em live presidencial, mais uma vez contra as medidas de fechamento e isolamento social, salta à vista a ideia pervertida, narcísica, belicosa e infantil de liberdade bolsonarista. Uma confrontação contra a autoridade, seja ela sanitária, afirmando o desejo mágico que brota da vontade individual: "não quero usar máscara", "não sou obrigado", "não quero usar cinto de segurança na cadeirinha, não sou obrigado". Por uma alquimia ideológica, essa ideia mistura-se à da liberdade neoliberal e à da liberdade religiosa, como comenta Emanuel Freitas em seu artigo nesse dossiê. Aqui, a ambiguidade aumenta, pois, se de um lado, afirma-se a independência do indivíduo, o poder mágico da evocação do nome de Deus (confissão positiva), a aceitação individual da salvação; por outro, celebra-se a constante subordinação individual a um poder divino maior e superior, manifestado de diversas formas, diante do qual cada um deve curvar-se, (“todo joelho se dobrará, toda lingua proclamará"!) e que se manifesta pelos mediadores, o pastor, o ungido de Deus, o intocável, na leitura reacionária-conservadora.

Em Karl Marx, a filosofia da história é brincalhona e mordaz, acontece como tragédia e farsa e, dentro desta, pode vir como grotesco-burlesco ou como bufão-drama.Assim, umdosmaisinstigantes exemplos, por mesclar estupidez, limitação cognitiva, religião mágica, culto político-reacionário, ideia de liberdade infantil absoluta e sujeição acrítica, ocorreu na quinta-feira outonal de março, 25. Um grupo realizou uma espécie de ato de culto da religião bolsonarista em São Leopoldo, no Rio Grande do Sul, contra o lockdown e pelo "tratamento precoce". Não existe tratamento precoce contra Covid-19. Sabe-se, por larga comprovação de estudos médico-científicos, que os remédios recomendados de forma mágicocelebrativa pelo presidente meses a fio afetam o figado, os rins e o coração; no limite, seu uso descuidado causa a morte. A convocação do ato pregava a "luta por liberdade" e "contra a tirania do prefeito" Ary José Vanazzi (PT), defensor de medidas restritivas. Numa praça perto da sede da prefeitura, um pequeno grupo 
de manifestantes bate continência para uma caixa gigante de cloroquina. Erguem paus com a bandeira nacional ou a jogam sobre os ombros, tornando-a um objeto sagrado de sua religião mágico-liberticida. Por fim, executaram o hino nacional durante a homenagem.A religião e a Covid-19, entrelaçam-se. No ápice, tem-se a religião da quarentena mal feita, o cloroquinismo.

Há obstas, sabe-se, à narrativa que aqui se contatal como está. Condições sociais e politicas distintas, agentes coletivos e redes de poder em diferentes configurações, incluindo religiosas. Mas, há linhas estruturais ou de continuidade atravessando múltiplas temporalidades e contextos que, por hora, propomos, mas sem desenrolar todo o papiro, deixar para comentar em outra ocasião. Assim como fez o documentário Evangélicos e a Covid-19: "Por Suas Palavras Sereis Condenados", do Laboratório de Improbabilidades Infinitas $\left(\mathrm{LABI}^{2}\right)$, optamos por enfatizar nesse comentário final as expressões religiosas que sussurram aos ouvidos do poder. Há coisas feitas em matéria de religião que têm consequências gerais, para todos, e não apenas aos da mesma fé. Nesses tempos de sindemia em que vivemos, algumas tomaram proporções sindemônicas.

\section{Referências bibliográficas}

BERGER, Peter. O dossel sagrado: elementos para uma sociologia da religião. São Paulo: Paulinas, 1989.

BERGER, Peter.Os múltiplos altares da modernidade: rumo a um paradigma da religião numa época pluralista. Petrópolis: Vozes, 2017.

CABELO, Mariangela; GHIRALDELli JR., Paulo (Org.). Pandemia e Pandemônio: Ensaios sobre biopolítica no Brasil. São Paulo: CEFA Editorial, 2020.

ESPOSITO, Roberto. Bios: biopolítica e filosofia Lisboa. Edições 70, 2010.

FOUCAULT, Michel. História da Sexualidade I: a vontade de se saber. $13^{\mathrm{a}}$ ed., Rio de Janeiro: Edições Graal, 1999.

FOUCAULT, Michel.O nascimento da biopolitica. Lisboa: Edições 70, 2010.

NEGRI, Tony; HARDT, Michael. Assembly: organização multitudinária do comum.São Paulo: Editora Filosófica Politeia, 2018.

SINGER, Merrill. Introduction to syndemics: a critical systems approach to public and community health. San Francisco: Jossey-Bass, 2009.

\section{Fontes Documentais Digitais}

BOLSONARO, Jair. Live Semanal do Presidente Jair Bolsonaro. Disponivel em: https://www.youtube.com/watch?v=g81BcbOVy5c\&t=73s\&ab_channel=UOL Acesso em 25 de março de 2021. 
FRAGÃO, Luísa. Bolsonaristas batem continência para caixa gigante de cloroquina no RS. 26 de março. Disponivel emhttps:// revistaforum.com.br/coronavirus/bolsonaristas-batem-continenciapara-caixa-gigante-de-cloroquina-no-rs / Acesso em 26 de março de 2021.

MING, Celso. A pandemia não terá ido embora enquanto não for extirpada em todo o planeta. Estado de São Paulo, 26 de março de 2021. Disponivel emhttps: //economia.estadao.com.br/noticias/geral,quinze-meses-de-pandemia,7000366 1929. Acesso em 26 de março 2021.

\footnotetext{
${ }^{1}$ https://noticias.uol.com.br/politica/ultimas-noticias/2021/04/18/cpi-da-covid-tcu-relatoriosenado-ministerio-da-saude-pandemia-coronavirus.htm?cmpid=copiaecola. Acesso em 25 de março de 2021.

2Disponível emhttps://g1.globo.com/bemestar/coronavirus/noticia/2021/03/25/brasil-registrarecorde-com-quase-100-mil-novos-caos-de-covid-em-um-dia-mortos-chegam-a-3037-mil.ghtml. Acesso em 25 de março de 2021.

3 Disponivel em: https://g1.globo.com/bemestar/coronavirus/noticia/2021/03/25/brasil-tem-63mil-pacientes-com-covid-19-na-fila-por-leitos-de-uti-aponta-conselho-de-secretarios.ghtml.Acesso em 25 de março de 2021.

4 Disponivel em: https://g1.globo.com/bemestar/coronavirus/noticia/2021/03/25/brasil-tem-63mil-pacientes-com-covid-19-na-fila-por-leitos-de-uti-aponta-conselho-de-secretarios.ghtml. Acesso em 25 de março de 2021.

5 Disponivel emhttps://www.youtube.com/watch?v=VUIDliD2MVo\&ab_channel=REDEVIDA. Acesso em 25 de março de 2021.

6Disponivel emhttps://www.bbc.com/portuguese/brasil-56485687. Acesso em de 25 março de 2021.

${ }^{7}$ Disponivel emhttps://youtu.be/RvUASfKB_-s. Acesso em de 25 março de 2021.
} 